\title{
Behavioral responses of the Iberian waterfrog, Pelophylax perezi (Seoane, 1885), to three nitrogenous compounds in laboratory conditions
}

\author{
Andrés Egea-Serrano • Miguel Tejedo ·
}

Mar Torralva

\begin{abstract}
Several studies have assessed the effects of nitrogenous compounds on amphibian behavior. However, few have focused on the effects of their combination with other stressors or on the variation of the response to pollutants among populations. We analyzed the effect of nitrogenous compounds $\left(\mathrm{NH}_{4}{ }^{\text {? }} ; \mathrm{NO}_{2}{ }^{-} ; \mathrm{NO}_{3}{ }^{-}\right.$, both alone and in combination) on larval behavior (activity level and location in the water column) in four populations of Pelophylax perezi naturally exposed to different levels of eutrophication. Larval activity was highest and use of the bottom of the experimental beaker was lowest at lower concentrations of nitrogenous compounds acting singly, these responses being minimal and maximal, respectively, at both control and higher concentrations. This pattern appears to fit to an hormetic reponse. Additionally, the combination of nitrogenous compounds affected more severely the response variables than when ammonium or nitrite acted singly according to an additive model. Populations inhabiting highly polluted aquatic habitats marginally showed higher activity level than the populations from less polluted environments, especially when larvae were exposed to ammonium or when nitrite appeared in combination with other nitrogen forms. Levels of activity correlated positively with larval final mass. Moreover, for similar levels of activity, larvae from polluted populations had higher growth rates than those coming from reference
\end{abstract}

A. Egea-Serrano (\&) M. Torralva

Department of Zoology and Physical Anthropology,

University of Murcia, 30100 Murcia, Spain

e-mail: aegea@um.es

M. Tejedo

Department of Evolutionary Ecology, Estación Biológica de Doñana, CSIC, Avda. Américo Vespucio s/n, 41092 Sevilla, Spain populations which suggests interdemic differences in behavioral sensitivity to nitrogenous pollutants.

Keywords Populational divergence Nitrogenous compounds pollution Nitrogenous mixtures Amphibians Activity Location in the water column

\section{Introduction}

Human activities, such as farming and fossil fuel combustion, have increased the concentration of nitrogenous compounds in the environment (Ritter and Bergstrom 2001; Vitousek et al. 1997). As a consequence, pollution by such compounds is widespread (Carpenter et al. 1998) and is expected to increase in the future (Galloway et al. 2003; Tilman et al. 2001). Thus, a current challenge is to understand how nitrogenous may impact organisms in nature.

Among the many organisms that might be affected in nature, there is growing interest in analyzing the impact of nitrogenous compounds on amphibians (see review by Marco and Ortiz-Santaliestra 2009). As a result, both lethal and sublethal effects have been reported for ammonium, nitrite and nitrate (e.g., Griffis-Kyle 2007; Marco et al. 1999; Xu and Oldham 1997) and investigators have discovered a great deal of intraspecific and interspecific variation in tolerance (Egea-Serrano et al. 2009a; Johansson et al. 2001; Marco et al. 1999).

Past studies have also demonstrated that the effects of nitrogenous compounds may be exacerbated when combined with other stressors. For example, nitrogenous fertilizers combined with pesticides (Boone et al. 2005), UV-B radiation (Hatch and Blaustein 2000, 2003; Macías et al. 2007) or low pH (Hatch and Blaustein 2000) can 

affect amphibian larvae more severely than when exposed to the fertilizer alone. In nature, nitrogenous compounds experience reduction and oxidation processes, resulting in mixtures of several different forms of inorganic nitrogen including ammonium, nitrite and nitrate (e.g., Atlas and Bartha 2002; Vidal-Abarca et al. 2000). Despite this fact, few studies have analysed the impact of different combinations of nitrogenous compounds on amphibian larvae (Egea-Serrano et al. 2009a). Moreover, although there is evidence of population-level variation in tolerance to nitrogenous compounds (Egea-Serrano et al. 2009a; Hatch and Blaustein 2003; Hecnar 1995; Johansson et al. 2001; Shinn et al. 2008), information on intraspecific differences among populations in the sensitivity to nitrate compounds is still scarce. Such information is urgently needed to understand the potential of a given species to adapt to this kind of pollution.

Pollutants such as pesticides and fertilizers can affect larval behavior, often causing reductions in activity (Bridges 1997, 1999; Hatch and Blaustein 2000; Hecnar 1995; Shinn et al. 2008; Xu and Oldham 1997). Decreases in tadpole activity may lead to reduced feeding rates and energy intake (Horat and Semlitsch 1994) and reduced competitive ability (Dayton and Fitzgerald 2001), which may slow growth and development (Alford and Harris 1988). Slower growth and development can make tadpoles more susceptible to pond desiccation (Bridges 1997) or cause a longer time of exposure to predators (Wilbur et al. 1983). In addition, pollutants such as nitrogenous compounds can increase blood methaemoglobin concentration (Huey and Beitinger 1980a). Because this protein cannot bind or transport oxygen, this outcome can cause tissue hypoxia and suffocation (OECD 1986; Unites States EPA 1986). In response to reduced oxygen, many species of tadpoles increase their rate of atmospheric oxygen uptake by bobbing for atmospheric oxygen, thereby affecting their location in the water column (Huey and Beitinger 1980b; Marco and Blaustein 1999). Such an effect will increase swimming activity and may move tadpoles away from food sources and reduce their feeding rate (Warkentin 1992).

To understand the impacts of nitrogenous compounds, alone and in combination, on amphibians, we used the Iberian waterfrog (Pelophylax perezi). This waterfrog is widespread throughout the Iberian Peninsula and Southern France (Llorente and Arano 1997), inhabiting mainly permanent water bodies as larvae and adults (Díaz-Paniagua 1990; Docampo and Vega 1990; Egea-Serrano et al. 2005; Martín et al. 2006). As a consequence of farming practices (one of the most important nitrogen sources in nature, e.g. Ritter and Bergstrom 2001), these habitats may hold high concentrations of different nitrogen forms (e.g. at southeastern Iberian Peninsula, point simple sample: $154.6 \mathrm{mg} \mathrm{NH}_{4}{ }^{?} / \mathrm{L} ; 74.4 \mathrm{mg} \mathrm{NO}_{2}^{-} / \mathrm{L} ; 333 \mathrm{mg} \mathrm{NO}{ }_{3}^{-} / \mathrm{L}$,
Suárez, personal communication). Therefore, this species might be exposed to nitrogen pollution throughout its life cycle. Moreover, P. perezi larvae spend most of their time on the benthos, at least in laboratory conditions (DíazPaniagua 1987), which would suggest that environmental conditions that cause them to move away from the benthos may have negative effects on larval fitness. Finally, past work has demonstrated population-level variation in survival and other fitness-related traits in response to different nitrogenous compounds (Egea-Serrano et al. 2009a).

Using P. perezi, the aims of the present study were the following: (1) to determine the effects of the exposure to different concentrations of ammonium chloride, sodium nitrite and sodium nitrate, and to the combination of high concentration of the latest compound with ammonium and nitrite on the activity and location of tadpoles in the water column; (2) to assess the effects of the exposure to the combination of high concentration of the sodium nitrate with different concentrations of ammonium chloride and sodium nitrite on the activity and location of tadpoles in the water column; and, (3) to evaluate whether there is evidence of divergence between populations in the behavioral traits undergoing different exposure histories to nitrogenous pollution. We predicted that tadpoles from polluted environments would be significantly more tolerant to nitrogen exposures by exhibiting higher levels of activity and movement through the water column, food consumption and body mass.

\section{Materials and methods}

\section{Studied populations}

Four populations of P. perezi located in the Segura River basin (SE Iberian Peninsula) were selected. This basin has been reported as one of the most arid of Iberian Peninsula (Vidal-Abarca et al. 1987), and a trend towards eutrophication of the water bodies located at this basin has been described since at least the 1980s (Ballester 2003). The selected populations were naturally exposed to different levels of nitrogen pollution. Two of these populations, corresponding to the permanent headwater stream Río Chícamo $\left(38^{\circ} 12^{0} \mathrm{~N}, 001^{\circ} 03^{\circ} \mathrm{W} ; 170.3 \mathrm{~m}\right.$ above sea level) and to the semipermanent headwater stream Rambla Tejera $\left(38^{\circ} 11^{\circ} \mathrm{N}, 002^{\circ} 07^{\circ} \mathrm{W} ; 1,197.9 \mathrm{~m}\right.$ above sea level) (C1 and C2 hereafter), showed low nutrient concentration (C1: less than $5.1 \mathrm{mg} \mathrm{N}-\mathrm{NO}_{3}{ }^{-} / \mathrm{L}$ (Vidal-Abarca et al. 2000); C2: less than $2.1 \mathrm{mg} \mathrm{NO}_{3}{ }^{-} / \mathrm{L}$, unpublished data). The terrestrial environment of these populations contains bush on marls (C1) or to a mixture of bush and pine trees on limestone lithology (C2). 
The other two populations have a history of nitrogen pollution. Rambla del Garruchal $\left(37^{\circ} 57^{\circ} \mathrm{N}, 001^{\circ} 04^{\circ} \mathrm{W}\right.$; $346.0 \mathrm{~m}$ above sea level; hereafter $\mathrm{P} 1$ ), is a semipermanent headwater stream which has been exposed to nitrate concentrations as high as $162.1 \mathrm{mg} \mathrm{NO}_{3}{ }^{-} / \mathrm{L}$ for 22 years (Ballester 2003) due to intensive farming activities and subsequent run-off in its basins. Campus of Espinardo $\left(38^{\circ} 01^{0} \mathrm{~N}, 001^{\circ} 10^{\circ} \mathrm{W}, 96.3 \mathrm{~m}\right.$ above sea level; hereafter $\mathrm{P} 2$ ), is a small artificial pool located at the Espinardo Campus of the University of Murcia. Although no data concerning nutrient concentrations are available for this population, episodic blooms of filamentous algae occurring at least for 10 years (unpublished data) suggest substantial levels of eutrophication. The terrestrial environment of P1 contains pine trees on heterogeneous carbonated materials although most of the stream course has been largely modified and is dominated by intensive livestock farming. The terrestrial environment of P2 is a suburban landscape. The geographical separation between populations ranged from 12.0 to $95.2 \mathrm{~km}$.

\section{Experimental design and response variables}

Five different egg masses of P. perezi were collected from each of four populations. P. perezi females attach egg clutches to aquatic vegetation (González de la Vega 1988; unpublished data). To avoid stressing embryos, egg masses were not separated from the attached aquatic vegetation, keeping embryo handling to a minimum. This procedure allowed to confirm that the number of eggs necessary to perform the experiment had been collected at least, but prevented us from accurately estimating either the exact number or the range of eggs collected per mass at each study population. All egg masses were collected during 4-7 April 2006 and the developmental Gosner stage of the embryos ranged from 15 to 21 (Gosner 1960); there were no differences among populations in developmental stage (Chi-square, P $\mathbf{2}$ 0.05). Since the aim of field work was to collect eggs, we did not collect any environmental data (e.g. water temperature) on the aquatic habitats at the time of collection.

During transport back to the lab, the egg masses were stored in 22-L plastic aquaria containing $8 \mathrm{~L}$ of water from the natal pond. Eggs were taken to the laboratory in less than $3 \mathrm{~h}$, and then transferred to $12-\mathrm{L}$ glass aquaria containing dechlorinated tap water $(\mathrm{pH}=8.39$; conductivity $\left.=985 \mathrm{IS} / \mathrm{cm} ; 0.002 \mathrm{mg} \mathrm{NO}_{2}{ }^{-} / \mathrm{L} ; 4.69 \mathrm{mg} \mathrm{NO}_{3}{ }^{-} / \mathrm{L}\right)$. In all cases, no embryos hatched prior to arriving to the laboratory. Embryos from the same population of origin were pooled in the field and reared in the same aquarium in the laboratory.

Fully arbitrarily selected larvae were assigned to each of the 11 treatments (Table 1). At Gosner stage 25, the
Table 1 Target nominal concentrations to larvae of Pelophylax perezi were exposed in the present study

\begin{tabular}{|c|c|}
\hline Treatment & Concentration \\
\hline 1 & 0 \\
\hline 2 & $1.35 \mathrm{mg} \mathrm{NH}_{4}{ }^{?} / \mathrm{L}$ \\
\hline 3 & $13.5 \mathrm{mg} \mathrm{NH}_{4}{ }^{?} / \mathrm{L}$ \\
\hline 4 & $6.67 \mathrm{mg} \mathrm{NO}_{2}^{-} / \mathrm{L}$ \\
\hline 5 & $66.7 \mathrm{mg} \mathrm{NO}{ }_{2}^{-} / \mathrm{L}$ \\
\hline 6 & $36.47 \mathrm{mg} \mathrm{NO}_{3}^{-} / \mathrm{L}$ \\
\hline 7 & $364.7 \mathrm{mg} \mathrm{NO}_{3}^{-} / \mathrm{L}$ \\
\hline 8 & $\begin{array}{l}1.35 \mathrm{mg} \mathrm{NH}{ }^{?} / \mathrm{L}^{-} ? 364.7 \mathrm{mg} \mathrm{NO}_{3}^{-} / \mathrm{L} \text { ? } \\
\quad 6.67 \mathrm{mg} \mathrm{NO}_{2}^{-} / \mathrm{L}\end{array}$ \\
\hline 9 & $\begin{array}{l}1.35 \mathrm{mg} \mathrm{NH}{ }_{4}^{?} / \mathrm{L}^{?} ? 364.7 \mathrm{mg} \mathrm{NO}_{3}^{-} / \mathrm{L} ? \\
\quad 66.7 \mathrm{mg} \mathrm{NO}_{2}^{-} / \mathrm{L}\end{array}$ \\
\hline 10 & $\begin{array}{l}13.5 \mathrm{mg} \mathrm{NH}{ }^{?} / \mathrm{L} ? 364.7 \mathrm{mg} \mathrm{NO}_{3}^{-} / \mathrm{L} ? \\
\quad 6.67 \mathrm{mg} \mathrm{NO}_{2}^{-} / \mathrm{L}\end{array}$ \\
\hline 11 & $\begin{array}{l}13.5 \mathrm{mg} \mathrm{NH}_{4}{ }^{?} / \mathrm{L} ? 364.7 \mathrm{mg} \mathrm{NO}_{3}^{-} / \mathrm{L}^{?} \text { ? } \\
\quad 66.7 \mathrm{mg} \mathrm{NO}_{2}^{-} / \mathrm{L}\end{array}$ \\
\hline
\end{tabular}

Note that concentrations were not confirmed using analytical chemistry

tadpoles were transferred to 1-L plastic beakers containing $500 \mathrm{~mL}$ of the treatment solutions. Ammonium, nitrite and nitrate concentrations were prepared using $\mathrm{NH}_{4} \mathrm{Cl}, \mathrm{NaNO}_{2}$ and $\mathrm{NaNO}_{3}$, respectively, and dechlorinated tap water. For each ion two concentrations (low or high, Table 1) were selected to assess and magnify any subtle effect that may have not been detected at lower concentration. In all cases, these concentrations were representative of those naturally occurring in the field in the Segura River basin (e.g. point simple sample: $154.6 \mathrm{mg} \mathrm{NH}_{4}{ }^{?} / \mathrm{L} ; 74.4 \mathrm{mg} \mathrm{NO}_{2}{ }^{-} / \mathrm{L}$; $333 \mathrm{mg} \mathrm{NO}_{3}{ }^{-} / \mathrm{L}$, Suárez, personal communication). Since a major objective of the present study was to assess the impact of the treatments on sublethal parameters, the concentrations selected for ammonium and nitrite were lower than those cited in environmental samples because preliminary tests showed that higher concentrations produced high larval mortality after short-term exposure (Egea-Serrano et al. 2009b). It is important to note that we calculated nominal concentrations but did not test either the nominal or the actual concentrations using analytical chemistry. Each beaker contained one tadpole. The movement of eggs and larvae was always done using a $10 \mathrm{~cm}^{2}$ piece of $1 \mathrm{~mm}$ mesh. The study species can lay a mean value of 2,309 eggs (Hotz et al. 1994), the same female being able to lay eggs at several times during the breeding season (Hotz et al. 1994). Size of the egg masses is very variable, ranging from 7,160 eggs to hundreds or, as in the case of the study populations, small masses of only 30-40 eggs (García-París 1985; González de la Vega 1988; Vidal 1966). Moreover, the reproduction of this species is positively correlated with environmental temperature 
(Richter-Boix et al., 2006), which means significant interpopulation and interanual variation of its breeding period (Richter-boix et al. 2006; review Egea-Serrano 2006). Therefore, and considering that egg collection had to be done during the same period for the four studied populations to get embryos at the same developmental stage, breeding strategy and interpopulational variation in breeding season would explain that the number of eggs collected was different for the different study populations, which determined the number of replicates for each population. Therefore, for C1 and C2 populations, each treatment was replicated seven times, whereas for P1 and P2 populations, it was repeated five times (i.e. seven and five beakers per treatment, respectively).

A sample of 13-15 experimental beakers were arbitrarily selected for each treatment to measure water $\mathrm{pH}$, temperature $\left({ }^{\circ} \mathrm{C}\right)$, conductivity $(\mathbf{I S} / \mathrm{cm})$ and salinity $(\mathrm{g} / \mathrm{L})$. Measurements were taken just after restoring treatments for the first time. Treatments did not affect $\mathrm{pH}\left(\mathrm{F}_{10,149}=1.400\right.$; $\mathrm{P}=0.167)$ or temperature $\left(\mathrm{F}_{10,149}=0.400 ; \mathrm{P}=0.925\right)$. However, conductivity $\left(\mathrm{F}_{10,149}=390.0 ; \mathrm{P}=0.0001\right)$ and salinity $\left(\mathrm{F}_{10,149}=524.330 ; \mathrm{P}=0.0001\right)$ were significantly higher for those treatments assigned high concentrations of ammonium, nitrite and nitrate, isolated or combined (see Egea-Serrano et al. 2009a for more details).

Larvae were fed every 3 days using dry dog chow pellets (250-350 mg). Although dog chow pellets were not characterized as a source of either nutrients nor contaminants, it is unlikely that they biased the impact of the treatments reported in the present study by significantly increasing trace contaminant or nutrient concentration in the experimental beakers because treatments were renewed every 2 days. Larvae were exposed to the chemicals for 21 days under laboratory conditions $\left(* 25^{\circ} \mathrm{C}\right.$ with indoor lighting on a 12:12 h dark:light cycle). Water was renewed and treatments reapplied every 2 days.

At days 2, 4, 7, 14 and 21 after the beginning of the experiment (day 1 ) we recorded activity (defined as presence of swimming or tail or feeding movements) and location in the water column (defined as whether or not a tadpole was on the bottom of the beaker) using the point sampling method (Altmann 1974). Only one observation was made on each beaker on each sampling date. To reduce the likelihood of assigning a given larva to a wrong category for either activity or location in the water column, each larva was observed for $30 \mathrm{~s}$. If a tadpole was moving during this period, it was scored as active. If a tadpole stayed mostly or totally on the bottom of the experimental beakers during this period, it was scored as being on the bottom of the beakers. To keep disturbance to a mininum, larvae were observed from a distance of $1 \mathrm{~m}$ ( $\mathrm{Xu}$ and Oldham 1997).
Larval mass was measured at the end of the experiment. In addition, we quantified food consumption at days 7, 14 and 21 using the methodology proposed by Rist et al. (1997). A preweighed dog chow pellet (250-350 mg) was placed in each beaker with no other food source. After $24 \mathrm{~h}$, the uneaten food was removed, dried again for $24 \mathrm{~h}$ at $50^{\circ} \mathrm{C}$ and weighed. To correct for any bias in the estimates due to the loss of food by its handling or physical dilution in water, a correction factor was calculated (EgeaSerrano et al. 2009a). To that end, a pilot study was performed with 50 dried dog chow pellets (205-350 mg). Each one was weighed, left in water without larvae for $24 \mathrm{~h}$ and weighed again after being dried for $24 \mathrm{~h}$ at $50^{\circ} \mathrm{C}$. Final dried mass of the pellets (y) was regressed against their initial dried mass before being submerged (x), obtaining the following regression equation: $\mathrm{y}=$ -0.0082 ? 0.8725x $\left(\mathrm{R}^{2}=0.988, \mathrm{P}=0.0001, \mathrm{~N}=50\right)$.

The initial dried mass of each chow pellet $(\mathrm{x})$ was introduced in this regression model to determine its final dried mass after removing the loss due to handling or dilution (y). The difference between this mass and the final dried mass weighed after chow pellets were in the experimental beaker with the larvae provided the amount of food eaten by each larva.

\section{Analysis of data}

Larval activity and location in the water column were analysed separately by General Linear Models (GLM). The dependent variables were the number of times a tadpole was active and the number of times a tadpole was on the bottom of the beaker. Independent factors were environment of origin (reference or polluted), population (nested within environment), chemical treatment, and their interactions. Larval mortality was recorded during the experiment (Egea-Serrano et al. 2009a). Because the major objective of our study was to characterize the impact of nitrogenous compounds on the behavioral responses for the duration of the experiment, only larvae surviving at the end of the experiment were included in the analyses to avoid bias from different sensitivity to pollution. We used post hoc HSD Tukey tests for pair-wise comparisons for the treatment factor. Additionally, each nitrogenous compound was analysed separately for each studied variable to examine in more detail the effects of compound concentrations and mixtures. To do so, treatments containing the compound of interest were selected and assigned the proper category of the factors concentration (low or high) and mixture (single or combined with the rest of compounds, regardless their concentration). Environment of origin, concentration, mixture and their different interactions were included as factors. To analyze for the effect of population 
of origin, this factor was also included in the analyses, nested within environment.

The overall effect of environment of origin, population of origin, nitrogenous treatment and their interaction on final mass and food consumption is not reported here because it was reported elsewhere (Egea-Serrano et al. 2009a). Nevertheless, to assess the relationship between activity, location in the water column and final mass and food consumption, Pearson correlation analyses were performed, both globally and for those treatments involving ammonium, nitrite and nitrate separately. In addition, analyses of covariance (ANCOVAs) were performed to specifically assess the impact of highly polluted treatments and environment of origin on food consumption and final mass after correcting for activity level. For both response variables, treatment (control or highly polluted [category including only treatments 3, 5, 7 and 11]) or environment of origin (reference or polluted) were considered as independent factors in separate ANCOVAs and in all cases activity level was included as a covariate.

All variables were log-transformed (mass and food consumption: $\log \mathrm{x}$; activity and location in the water column: $\log (\mathrm{x}$ ? 1)). Analyses were performed with SPSS $^{\circledR}$ v. 15.0 statistical package. In all cases a significance level of $\mathrm{P} \backslash 0.05$ was selected and descriptive statistics were expressed as mean $\pm 1 \mathrm{SE}$.

\section{Results}

\section{Effects on activity}

For both the overall and separate analyses, tadpole activity was lower for high-N concentrations of nitrogenous compounds than for low-N concentrations (Tables 2, 3; Fig. 1). Futhermore, separate analyses revealed that the combination of nitrite with other nitrogenous compounds increased larval activity in relation to its effect acting alone (Table 3; Fig. 1). When the control treatment was compared with either lowand high-N treatments, we found a non-linear pattern in the activity response. Control and highly polluted treatments (treatments 3, 5, 7 and 11) induced similar activity (HDS Tukey's test, $\mathrm{P}=0.315$ ), which was lower than that for low nitrogen concentrations (treatment 2, 4 and 6) (HDS Tukey's test, $\mathrm{P} \backslash 0.017)$.

The environment of origin showed marginally significant effects on larval activity for both the overall analyses (Table 2), and when nitrite and nitrate were analysed separately. For ammonium, the environment of origin was significant (Table 3; Fig. 1). Larvae from polluted populations exhibited higher activity than those from reference populations. In addition, this response was more marked in the case of the exposure to nitrite in combination with other nitrogenous compounds (Table 3; Fig. 1).

\section{Effects on location in the water column}

Treatment marginally affected larval location in the water column (Table 2). Larvae exposed to control treatment were on the bottom of the beaker more times than larvae exposed to treatments 2, 4, 6 and 8 (Fig. 2). This effect was marginal (HSD Tukey test: $\mathrm{P}=0.063$ ) in response to treatment 3. Neither environment of origin nor population significantly affected larval location in the water column. Although the environment of origin 9 treatment interaction was not significant, population-specific tolerance was found (significant population 9 treatment interaction; Table 2; Fig. 2). Additionally, increased use of the bottom was found when ammonium was combined with other nitrogenous compounds relative to ammonium acting alone (Table 3; Fig. 2).

Table 2 Summary statistics for the GLM analyses performed on activity level and location in the water column of larvae of Pelophylax perezi exposed to different nitrogenous treatments (significant values appear in bold)

\begin{tabular}{lcrr}
\hline Source of variation & df numerator & df denominator & F \\
\hline Activity & & & P \\
$\quad$ Environment & 1 & 2.006 & 15.531 \\
Population (environment) & 2 & 26.880 & 1.405 \\
Treatment & 10 & 21.162 & 4.124 \\
Environment 9 treatment & 10 & 21.264 & 0.059 \\
Treatment 9 population (environment) & 19 & 171 & 0.003 \\
Location in the water column & & & 0.413 \\
Environment & 1 & 1.999 & 0.422 \\
Population (environment) & 2 & 23.505 & 0.152 \\
Treatment & 10 & 20.262 & 2.143 \\
Environment 9 treatment & 10 & 20.320 & 0.734 \\
Treatment 9 population (environment) & 19 & 171 & 0.140 \\
\end{tabular}


Table 3 Summary statistics for the GLM analyses on activity and location in the water column of larvae of Pelophylax perezi in the laboratory for particular nitrogenous elements: $\mathrm{NH}_{4}{ }^{?}, \mathrm{NO}_{2}{ }^{-}$, and $\mathrm{NO}_{3}{ }^{-}$, individually and in combination

\begin{tabular}{|c|c|c|c|c|c|c|c|c|c|c|c|c|c|}
\hline \multirow[t]{2}{*}{ Variable } & \multirow[t]{2}{*}{ Source of variation } & \multicolumn{4}{|c|}{$\mathrm{NH}_{4}{ }^{?}$} & \multicolumn{4}{|c|}{$\mathrm{NO}_{2}^{-}$} & \multicolumn{4}{|c|}{$\mathrm{NO}_{3}^{-}$} \\
\hline & & ndf & ddf & $\mathrm{F}$ & $\mathrm{P}$ & ndf & ddf & $\mathrm{F}$ & $\mathrm{P}$ & ndf & ddf & $\mathrm{F}$ & $\mathbf{P}$ \\
\hline \multirow[t]{8}{*}{ Activity } & Environment: ENV & 1 & 3.220 & 9.6485 & 0.0482 & 1 & 2.250 & 11.9281 & 0.0629 & 1 & 3.089 & 8.8621 & 0.0566 \\
\hline & Population (ENV) & 2 & 92 & 1.2739 & 0.2846 & 2 & 103 & 0.9886 & 0.3756 & 2 & 105 & 1.2391 & 0.2939 \\
\hline & Concentration (CON) & 1 & 92 & 3.9837 & 0.0489 & 1 & 103 & 8.9837 & 0.0034 & 1 & 105 & 3.5761 & $0.0614^{\mathrm{a}}$ \\
\hline & Mixture (MIX) & 1 & 92 & 0.8252 & 0.3661 & 1 & 103 & 9.0825 & 0.0032 & 1 & 105 & 3.5391 & $0.0627^{\mathrm{b}}$ \\
\hline & CON 9 MIX & 1 & 92 & 0.0704 & 0.7913 & 1 & 103 & 0.4912 & 0.4850 & NM & NM & NM & NM \\
\hline & ENV $9 \mathrm{CON}$ & 1 & 92 & 1.0735 & 0.3029 & 1 & 103 & 0.1120 & 0.7386 & 1 & 105 & 0.7125 & $0.4005^{\mathrm{a}}$ \\
\hline & ENV 9 MIX & 1 & 92 & 0.8058 & 0.3717 & 1 & 103 & 4.8799 & 0.0294 & 1 & 105 & 1.5885 & $0.2103^{\mathrm{b}}$ \\
\hline & ENV 9 CON 9 MIX & 1 & 92 & 0.4612 & 0.4988 & 1 & 103 & 0.0006 & 0.9806 & NM & NM & NM & NM \\
\hline \multirow[t]{8}{*}{ Location in the water column } & Environment: ENV & 1 & 2.479 & 0.4248 & 0.5699 & 1 & 2.189 & 0.0212 & 0.8965 & 1 & 2.177 & 0.5167 & 0.5415 \\
\hline & Population (ENV) & 2 & 92 & 3.0316 & 0.0531 & 2 & 103 & 1.3019 & 0.2764 & 2 & 105 & 6.9447 & 0.0015 \\
\hline & Concentration (CON) & 1 & 92 & 1.5575 & 0.2152 & 1 & 103 & 2.3766 & 0.1262 & 1 & 105 & 5.7715 & $0.0180^{\mathrm{a}}$ \\
\hline & Mixture (MIX) & 1 & 92 & 9.7227 & 0.0024 & 1 & 103 & 1.4023 & 0.2391 & 1 & 105 & 0.2478 & $0.6197^{b}$ \\
\hline & CON 9 MIX & 1 & 92 & 0.0026 & 0.9594 & 1 & 103 & 0.0567 & 0.8123 & $\mathrm{NM}$ & NM & NM & NM \\
\hline & ENV 9 CON & 1 & 92 & 0.0135 & 0.9079 & 1 & 103 & 0.0764 & 0.7828 & 1 & 105 & 0.0001 & $0.9924^{\mathrm{a}}$ \\
\hline & ENV 9 MIX & 1 & 92 & 0.0653 & 0.7989 & 1 & 103 & 1.1588 & 0.2842 & 1 & 105 & 0.1965 & $0.6585^{\mathrm{b}}$ \\
\hline & ENV 9 CON 9 MIX & 1 & 92 & 0.3223 & 0.5716 & 1 & 103 & 0.1275 & 0.7218 & NM & NM & NM & NM \\
\hline
\end{tabular}

Significant values are shown in bold

ndf Numerator degrees of freedom, ddf denominator degrees of freedom

a These sources of variation were estimated only for isolated $\mathrm{NO}_{3}-{ }^{\mathrm{b}}$ these sources of variation were estimated only for high concentration of $\mathrm{NO}_{3}{ }^{-}$; NM non measurable sources of variation

Influence of larval behavior on food consumption and mass

Overall, larval activity correlated positively with final larval mass and negatively with food consumption, especially for the single nitrite (Tables 4, 5). Time spent on the bottom of the beaker was only negatively correlated with food consumption in the case of ammonium and nitrate when analysed separately. For these ions, larvae spending more time on the bottom of the experimental beakers consumed less food (Table 5).

Although larval activity was similar among the control and treatments enriched with nitrogenous compounds (see "Results" section, effects on activity), final mass, once controlled for activity level, was smaller for highly polluted environments than for the control treatment (ANCOVA, treatment, $\mathrm{F}_{1,99}=5.977, \mathrm{P}=0.016$ ). Additionally, for a similar level of activity, larvae from polluted populations had higher growth rates than those coming from reference populations (ANCOVA, environment of origin $\mathrm{F}_{1,209}=16.155, \mathrm{P}=0.0001$, Fig. 3). In addition, food consumption was not different between environments (ANCOVA, environment of origin $F_{1,204}=2.394$, $\mathrm{P}=0.123)$.

\section{Discussion}

The behavioral responses of larval P. perezi to increasing concentrations of nitrogen-based chemicals showed a nonlinear trend, activity and use of the bottom of the beakers being minimal and maximal, respectively, at both control and higher concentrations. This pattern contrasts with the overall decrease of larval activity in nitrogen-enriched treatments (Hatch and Blaustein 2000; Hecnar 1995; Shinn et al. 2008; Xu and Oldham 1997) or with the increase of atmospheric oxygen uptake reported in previous studies (Huey and Beitinger 1980b; Marco and Blaustein 1999). Dose-response relationship is the major concept used to assess toxicological risk (Calabrese and Baldwin 2003), and linear threshold and non-threshold models have been traditionally employed to predict larval amphibian behavioral and developmental responses (e.g. Ortiz et al. 2004). However, sometimes organisms may perform an adaptive response to overcompensate low levels of stress, fitting to an U-shaped dose-response relationship commonly named hormesis (Calabrese and Baldwin 2002, 2003). Our results may be explained by considering that moderate levels of stress may have induced a compensatory response. It has been previously suggested that blood methemoglobin may 
Fig. 1 Mean larval activity ( \pm 1 SE) for four different Pelophylax perezi populations exposed to low and high concentrations of three nitrogenous compounds and to different combinations of them. Text in boldface indicates the higher concentration for the different ions used in the present study. Treatment codes are shown in brackets. Results of HDS Tukey's test $(\mathrm{a}=5 \%)$ performed for the factor treatment are shown (common underbars notation). Different lowercase letters above the data bars indicate differences within treatments according to HDS Tukey's test $(\mathrm{a}=5 \%)$. White bars reference populations; grey bars polluted populations

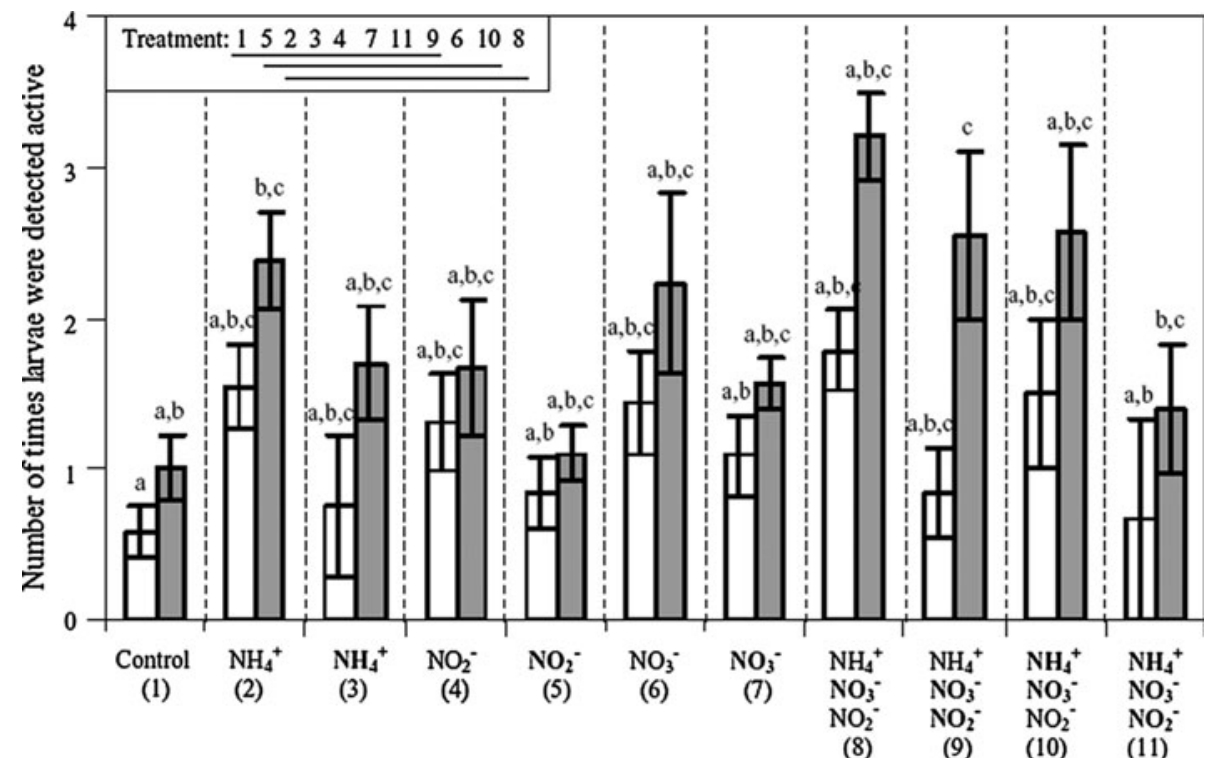

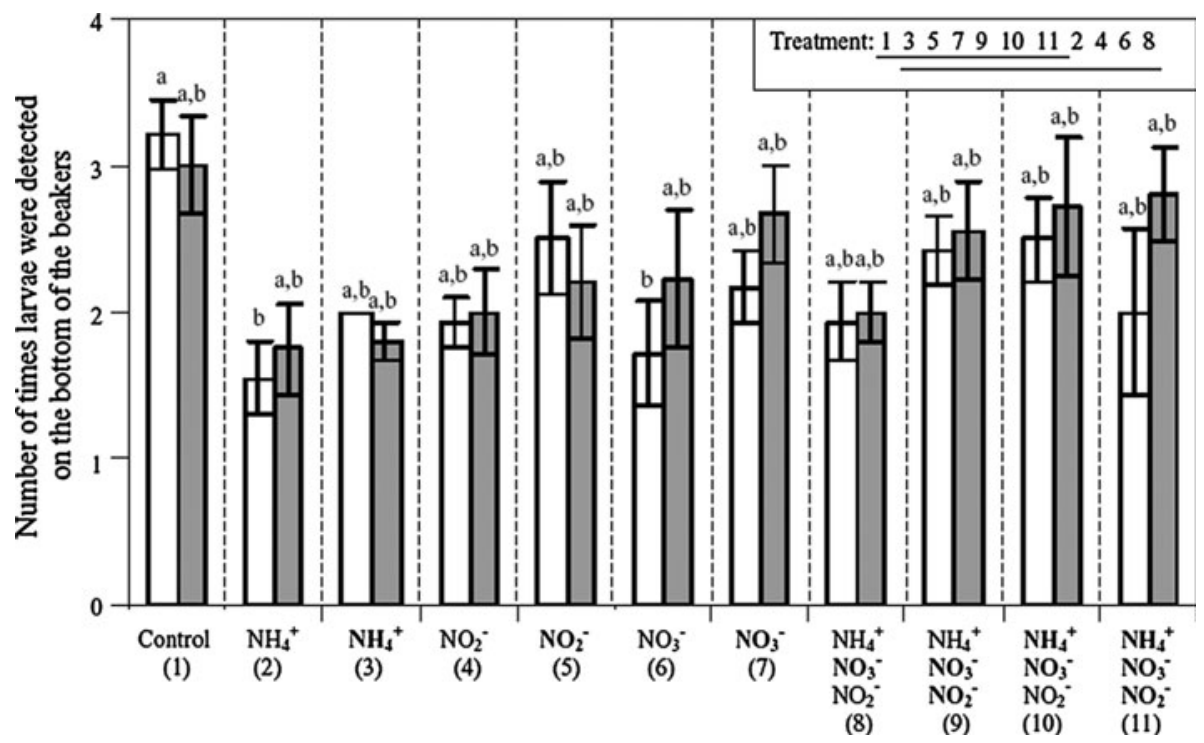

Fig. 2 Mean larval location in the water column $( \pm 1 \mathrm{SE})$ for four different Pelophylax perezi populations exposed to low and high concentrations of three nitrogenous compounds and to different combinations of them. Text in boldface indicates the higher concentration for the different ions used in the present study. Treatment codes are shown in brackets. Results of HDS Tukey's test

increase as a consequence of the exposure to nitrite (Huey and Beitinger 1980a). Thus, although air-gulping rates were not recorded, it makes sense to infer that larvae exposed to moderately polluted treatments may have been forced to increase atmospheric oxygen uptake to satisfy their oxygen demands. This possibility, together with the positive buoyancy it may represent (Feder and Wassersug 1984; Wasserssug and Feder 1983), may have determined both increased larval activity and use of the water column, as the negative correlation between activity and location in
( $\mathrm{a}=5 \%$ ) performed for the factor treatment are shown (common underbars notation). Different lowercase letters above the data bars indicate differences within treatments according to HDS Tukey's test (a $=5 \%$ ). White bars reference populations; grey bars polluted populations

the water column suggests. The absence of any behavioral response at the high- $\mathrm{N}$ treatments may be attributed to the fact that concentrations were high enough to prevent the compensatory response but not high enough to significantly reduce feeding or swimming activity through the water column. This explanation would suggest that the observed response would fit a hormetic response (Calabrese and Badwin 2002, 2003), supporting previous results (GriffisKyle 2007; Watt and Oldham 1995). Nevertheless, it has to be noticed that, although treatments were reapplied every 2 
Table 4 Summary statistics for Pearson correlation tests between larval behavior and fitness-related traits for the overall analysis

\begin{tabular}{|c|c|c|c|}
\hline Activity & $\begin{array}{l}\text { Location } \\
\text { in the } \\
\text { water } \\
\text { column }\end{array}$ & Mass & $\begin{array}{l}\text { Food } \\
\text { consumption }\end{array}$ \\
\hline
\end{tabular}

\begin{tabular}{lllll}
\hline $\begin{array}{l}\text { Activity } \\
\text { Pearson correlation }\end{array}$ & 1 & & & \\
P & & & & \\
N & 214 & & & \\
Location in the water & & & & \\
column & & & & \\
Pearson correlation & -0.391 & 1 & & \\
P & 0.0001 & & & \\
N & 214 & 214 & & \\
Mass & & & & \\
Pearson correlation & 0.207 & 0.025 & 1 & \\
P & 0.002 & 0.717 & & \\
N & 212 & 212 & 212 & \\
Food consumption & & & & \\
Pearson correlation & -0.171 & -0.103 & 0.042 & 1 \\
P & 0.014 & 0.141 & 0.546 & \\
N & 207 & 207 & 206 & 207 \\
\hline
\end{tabular}

Significant correlations are marked in bold

days, the results observed may be due to the fact that the actual concentrations significantly differed from nominal concentrations.

Polluted treatments negatively affected larval foraging ability (Egea-Serrano et al. 2009a) and this effect appears to be partially mediated via larval activity, since the two traits were negatively correlated. Paradoxically, final larval mass did not depend on the amount of food consumed. Additionally, for a constant activity level, control larvae attained larger sizes than similarly active tadpoles growing at nitrogen-enriched treatments. The exposure to chemicals can increase metabolic rate and activate detoxification pathways (Rowe et al. 1998; Wright and Wright 1996) which consumes energy. Therefore, our results may be explained by considering that larvae showing lower activity levels were so severely affected by treatments that they had to increase feeding efficiency to satisfy the energetic costs of maintenance and detoxification, leaving less energy to devote to growth. Such detoxification costs would also explain the mass reduction described by EgeaSerrano et al. (2009a) for high concentrations of ammonium or nitrite, thus suggesting that the degree to which activity affected mass was more severe for those larvae growing in polluted environments.

We found no significant correlation between food consumption and larval mass, neither overall nor when ammonium or nitrite were analysed separately. This lack of effect may be attributed to activity, that was both positively correlated with mass and negatively with food consumption. Therefore, the influence of food consumption on larval mass may be masked by the effect of larval activity.

Overall, neither food consumption nor larval mass were associated with location in the water column. Dog chow pellets stayed on the bottom of the beakers, once hydrated, and larvae of P. perezi mainly are benthic, at least under laboratory conditions (Díaz-Paniagua 1987). Thus, any significant influence of treatments on larvae moving away from the bottom of the beakers and, therefore, from food sources, should have produced a significant correlation between larval location in the water column and fitnessrelated traits. Nevertheless, such an effect was not detected, which may be because the correlation between location in the water column and larval activity was weak. However, when ammonium and nitrate were analysed separately, location in the water column was negatively correlated with food consumption. This result may suggest that tadpoles spending more time on the bottom of the beakers were so stressed that they could not increase food consumption to overcompensate the stress induced by treatments.

Some caution is warranted in considering the above interpretations of correlations among the studied variables. First, final mass reflects the influence of the treatments for the whole exposure period, whereas larval activity, location in the water column and food consumption were recorded at given days. This disparity regarding the ways of recording these variables may have masked the relationships among them. Therefore, future studies should record ethological endpoints daily to accurately assess whether the relationships found between the studied variables still hold.

The combination of nitrogenous compounds produced more severe effects on larval location in the water column or activity than when ammonium or nitrite were present alone, respectively. This scenario supports previous studies describing more severe effects when nitrogenous pollutants were combined with other stressing factors such as pesticides, UV-B radiation or low pH (Boone et al. 2005; Hatch and Blaustein 2000, 2003; Macías et al. 2007; but see Boone and Bridges-Britton 2006; Orton et al. 2006). However, some caution is needed when interpreting the harmful effects of nitrogenous combinations on larvae, since additive combinations of nitrogenous compounds also have a higher total nitrogen concentration (Egea-Serrano et al. 2009a). The lack of significant concentration 9 mixture interactions suggest the effects observed would correspond to an additive model (Berenbaum 1989), in contrast to another study with P. perezi (Egea-Serrano et al. 2009a) in which synergistic effects on mortality, food consumption and mass were found. 
Table 5 Summary statistics for Pearson correlation tests between larval behavior and fitness-related traits for ammonium, nitrite and nitrate separately

\begin{tabular}{|c|c|c|c|c|}
\hline & Activity & Location in the water column & Mass & Food consumption \\
\hline \multicolumn{5}{|l|}{ Ammonium } \\
\hline \multicolumn{5}{|l|}{ Activity } \\
\hline Pearson correlation & 1 & & & \\
\hline \multicolumn{5}{|l|}{$\mathrm{P}$} \\
\hline $\mathrm{N}$ & 102 & & & \\
\hline \multicolumn{5}{|c|}{ Location in the water column } \\
\hline Pearson correlation & -0.290 & 1 & & \\
\hline $\mathrm{P}$ & 0.003 & & & \\
\hline $\mathrm{N}$ & 102 & 102 & & \\
\hline \multicolumn{5}{|l|}{ Mass } \\
\hline Pearson correlation & 0.329 & -0.049 & 1 & \\
\hline $\mathrm{P}$ & 0.001 & 0.626 & & \\
\hline $\mathrm{N}$ & 101 & 101 & 101 & \\
\hline \multicolumn{5}{|l|}{ Food consumption } \\
\hline Pearson correlation & -0.118 & -0.310 & 0.035 & 1 \\
\hline $\mathrm{P}$ & 0.254 & 0.002 & 0.734 & \\
\hline $\mathrm{N}$ & 95 & 95 & 95 & 95 \\
\hline \multicolumn{5}{|l|}{ Nitrite } \\
\hline \multicolumn{5}{|l|}{ Activity } \\
\hline Pearson correlation & 1 & & & \\
\hline \multicolumn{5}{|l|}{$\mathrm{P}$} \\
\hline $\mathrm{N}$ & 113 & & & \\
\hline \multicolumn{5}{|c|}{ Location in the water column } \\
\hline Pearson correlation & -0.231 & 1 & & \\
\hline $\mathrm{P}$ & 0.014 & & & \\
\hline $\mathrm{N}$ & 113 & 113 & & \\
\hline \multicolumn{5}{|l|}{ Mass } \\
\hline Pearson correlation & 0.281 & -0.004 & 1 & \\
\hline$P$ & 0.003 & 0.965 & & \\
\hline $\mathrm{N}$ & 111 & 111 & 111 & \\
\hline \multicolumn{5}{|l|}{ Food consumption } \\
\hline Pearson correlation & -0.234 & -0.125 & 0.023 & 1 \\
\hline $\mathrm{P}$ & 0.016 & 0.202 & 0.817 & \\
\hline $\mathrm{N}$ & 106 & 106 & 105 & 106 \\
\hline \multicolumn{5}{|l|}{ Nitrate } \\
\hline \multicolumn{5}{|l|}{ Activity } \\
\hline Pearson correlation & 1 & & & \\
\hline \multicolumn{5}{|l|}{$\mathrm{P}$} \\
\hline $\mathrm{N}$ & 113 & & & \\
\hline \multicolumn{5}{|c|}{ Location in the water column } \\
\hline Pearson correlation & -0.444 & 1 & & \\
\hline $\mathrm{P}$ & 0.0001 & & & \\
\hline $\mathrm{N}$ & 113 & 113 & & \\
\hline \multicolumn{5}{|l|}{ Mass } \\
\hline Pearson correlation & 0.253 & 0.066 & 1 & \\
\hline $\mathrm{P}$ & 0.007 & 0.489 & & \\
\hline $\mathrm{N}$ & 112 & 112 & 112 & \\
\hline
\end{tabular}


Table 5 continued

\begin{tabular}{lllll}
\hline & Activity & Location in the water column & Mass & Food consumption \\
\hline Food consumption & & & 0.207 & 1 \\
Pearson correlation & 0.032 & -0.282 & 0.034 & 106 \\
$\mathrm{P}$ & 0.744 & 0.003 & 106 \\
$\mathrm{~N}$ & 106 & 106 & 106 \\
\hline
\end{tabular}

Significant correlations are marked in bold

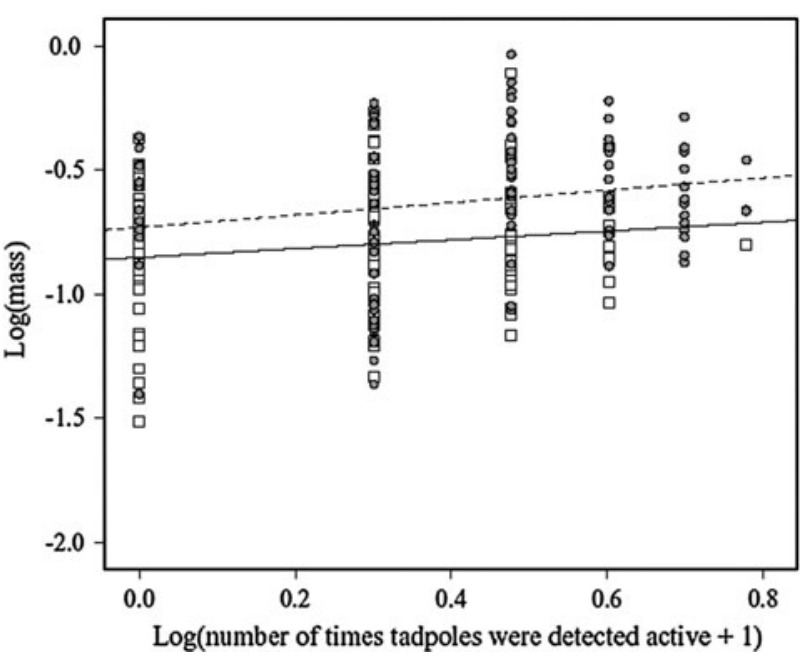

Fig. 3 Larval mass at the end of the experiment (21 days) as a function of their estimated activity levels of individuals from polluted and reference origin populations. Open squares and solid line reference populations; filled circles and dashed line polluted populations

Tadpole populations collected from highly polluted aquatic habitats showed higher activity levels than populations collected from less polluted environments. Moreover, for a similar level of activity, larvae from polluted populations had higher growth rates than those coming from reference populations, although food consumption did not differ. These findings, together with population-level differences in water column position and divergence in assimilation rates, suggest the existence of geographical variation in behavioral sensitivity and tolerance in P. perezi larvae to nitrogenous compounds. Since the studied populations may have been exposed to different nutrient concentration (Ballester 2003; Vidal-Abarca et al. 2000), an adaptive process, and even genetic adaptation, could be expected, as has been previously suggested for Rana temporaria (Johansson et al. 2001) and even for P. perezi larvae in survival and other larval fitness traits (Egea-Serrano et al. 2009a). However, other factors may mask the divergent responses observed. For instance, population divergence may be the response to other environmentally based factors such as maternal effects (Räsänen and Kruuk 2007). Since tadpoles from different egg masses were mixed, the factor family could not be included in the analyses and, consequently, maternal effects could not be accounted for. Moreover, egg masses were collected in the field and, consequently, selective mortality and/or acclimatization process in the localities of origin could be partially responsible for the responses observed (Freda and Dunson 1984; Räsänen et al. 2003). All these considerations make it difficult to assess the interpretation of an adaptive response of populations to nitrogenous pollution.

Two final considerations may be suggested. First, it has to be emphasized the relevance of considering behavior when assessing the impact of a stressor on amphibians, since the effects observed for a given variable may be the expression of ethological alterations. Second, some caution is needed when interpreting those studies reporting the lack of effect of a chemical on amphibians, since the responses of these vertebrates to pollutants are not always linear, as the present study points out.

Acknowledgments We thank Dr. María Luisa Suárez for her comments on eutrophication levels in the Segura River basin. We are indebted to Dr. Christine Bishop and one anonymous referee for reading and improving the manuscript. We also express our gratitude to Dr. Rick A. Relyea for his comments on the style and spelling of the English version of the manuscript. We acknowledge the Environmental Service of the Autonomous Government of Murcia, Spain, for providing the permits to collect the biological material used in this study. A. Egea-Serrano was supported by a Caja de Ahorros del Mediterráneo predoctoral fellowship.

\section{References}

Alford RA, Harris RM (1988) Effects of larval growth history on anuran metamorphosis. Am Nat 131:91-106

Altmann J (1974) Observational study of behavior: sampling methods. Behavior 49:227-267

Atlas RM, Bartha R (2002) Ecología microbiana y microbiología ambiental. Pearson Educación S.A., Madrid

Ballester R (dir) (2003) Los humedales de la Región de Murcia: Humedales y ramblas de la Región de Murcia. Murcia: Dirección General del Medio Natural, Consejería de Agricultura, Agua y Medio Ambiente, Región de Murcia

Berenbaum MC (1989) What is synergy? Pharmacol Rev 41:93-141

Boone MD, Bridges-Britton CM (2006) Examining multiple sublethal contaminants on the gray treefrog (Hyla versicolor): effects of an insecticide, herbicide and fertilizer. Environ Toxicol Chem 25:3261-3265 
Boone MD, Bridges CM, Fairchild JF, Little EE (2005) Multiple sublethal chemicals negatively affect tadpoles of the green frog, Rana clamitans. Environ Toxicol Chem 24:1267-1272

Bridges CM (1997) Tadpole swimming performance and activity affected by acute exposure to sublethal levels of carbaryl. Environ Toxicol Chem 19:1935-1939

Bridges CM (1999) Effects of a pesticide on tadpole activity and predator avoidance behavior. J Herpetol 33:303-306

Calabrese EJ, Baldwin LA (2002) Defining hormesis. Hum Exp Toxicol 21:91-97

Calabrese EJ, Baldwin LA (2003) Toxicology rethinks its central belief. Nature 421:691-692

Carpenter S, Caraco NF, Correll DL, Howarth RW, Sharpley AN, Smith VH (1998) Nonpoint pollution of surface waters with phosphorous and nitrogen. Ecol Appl 8:559-568

Dayton GH, Fitzgerald LA (2001) Competition, predation and the distributions of four desert anurans. Oecologia 129:430-435

Díaz-Paniagua C (1987) Estudio en cautividad de la actividad alimenticia de las larvas de siete especies de anuros. Rev Esp Herpetol 2:189-197

Díaz-Paniagua C (1990) Temporary ponds as breeding site of amphibians at a locality in Southwestern Spain. Herpetol J 1:447-453

Docampo L, Vega MM (1990) Contribución al estudio de la alimentación de Barbus bocagei (Steindachner, 1866), Phoxinus phoxinus (Linnaeus, 1758) y Rana perezi (Seoane, 1885) en ríos de Bizkaia. Sci Gerund 16:61-73

Egea-Serrano A (2006) Rana común-Pelophylax perezi. In: Salvador A, Martínez-Solano I (eds) Enciclopedia Virtual de los Vertebrados Españoles. Museo Nacional de Ciencias Naturales, Madrid. http://www.vertebradosibericos.org/. Accessed 28 Feb 2011

Egea-Serrano A, Oliva-Paterna FJ, Torralva M (2005) Selección de habitat reproductor por Rana perezi Seoane, 1885 en el NO de la Región de Murcia (SE Península Ibérica). Rev Esp Herpetol 19:113-125

Egea-Serrano A, Tejedo M, Torralva M (2009a) Populational divergence in the impact of three nitrogenous compounds and their combination on larvae of the frog Pelophylax perezi (Seoane, 1885). Chemosphere 76:869-877

Egea-Serrano A, Tejedo M, Torralva M (2009b) Estimating mean lethal concentrations of three nitrogenous compounds for the Iberian waterfrog, Pelophylax perezi (Seoane, 1885), larvae. Rev Esp Herpetol 23:107-116

Feder ME, Wassersug RJ (1984) Aerial versus aquatic oxygen consumption in larvae of the clawed frog, Xenopus laevis. J Exp Biol 108:231-245

Freda J, Dunson WA (1984) Sodium balance of amphibian larvae exposed to low environmental pH. Physiol Zool 57:435-443

Galloway JN, Aber JD, Erisman JW, Seitzinger SP, Howarth RW, Cowling EB, Cosby BJ (2003) The nitrogen cascade. Bioscience 53:341-356

García-París M (1985) Los anfibios de España. Ministerio de Agricultura, Pesca y Alimentación, Madrid

González de la Vega JP (1988) Anfibios y reptiles de la provincia de Huelva. ERTISA, Huelva

Gosner KL (1960) A simplified table for staging embryos and larvae with notes on identification. Herpetologica 16:183-190

Griffis-Kyle KL (2007) Sublethal effects of nitrite on eastern tiger salamander (Ambystoma tigrinum tigrinum) and wood frog (Rana sylvatica) embryos and larvae: implications for field populations. Aquat Ecol 41:119-127

Hatch AC, Blaustein AR (2000) Combined effects of UV-B, nitrate and low $\mathrm{pH}$ reduce the survival and activity level of larval Cascades frogs (Rana cascadae). Arch Environ Contam Toxicol 39:494-499
Hatch AC, Blaustein AR (2003) Combined effects of UV-V radiation and nitrate fertilizer on larval amphibians. Ecol Appl 13:10831093

Hecnar SJ (1995) Acute and chronic toxicity of ammonium nitrate fertilizer to amphibians from Southern Ontario. Environ Toxicol Chem 14:2131-2137

Horat P, Semlitsch RD (1994) Effects of predation risk and hunger on the behavior of two species of tadpoles. Behav Ecol Sociobiol 34:393-401

Hotz H, Uzzell T, Berger L (1994) Hemiclonal hybrid water frogs associated with the sexual host species Rana perezi. Zool Pol 39:243-266

Huey DW, Beitinger TL (1980a) Hematological responses of larval Rana catesbeiana to sublethal nitrite exposures. Bull Environ Contam Toxicol 25:574-577

Huey DW, Beitinger TL (1980b) Toxicity of nitrite to larvae of the salamander Ambystoma texanum. Bull Environ Contam Toxicol 25:909-912

Johansson M, Räsänen K, Merilä J (2001) Comparison of nitrate tolerance between different populations of the common frog, Rana temporaria. Aquat Toxicol 54:1-14

Llorente GA, Arano B (1997) Rana perezi. In: Pleguezuelos JM (ed) Distribución y Biogeografía de los anfibios y reptiles en España y Portugal. Asociación Herpetológica Española-Universidad de Granada, Granada, pp 164-166

Macías G, Marco A, Blaustein AR (2007) Combined exposure to ambient UVB radiation and nitrite negatively affects survival of amphibian early life stages. Sci Total Environ 385:55-65

Marco A, Blaustein AR (1999) The effects of nitrite on behavior and metamorphosis in Cascades frogs (Rana cascadae). Environ Toxicol Chem 18:946-949

Marco A, Ortiz-Santaliestra ME (2009) Pollution: impact of reactive nitrogen on amphibians. In: Heatwole $\mathrm{H}$, Wilkinson JW (eds) Amphibian biology, vol. 8, amphibian decline: diseases, parasites, maladies and pollution. Surrey Beatty \& Sons, Baulkham Hills, pp 3145-3185

Marco A, Quilchano C, Blaustein AR (1999) Sensitivity to nitrate and nitrite in pond-breeding amphibians from the Pacific Northwest, USA. Environ Toxicol Chem 18:2836-2839

Martín J, Luque-Larena JJ, López P (2006) Collective detection in escape responses of temporary groups of Iberian green frogs. Behav Ecol 17:222-226

OECD (1986) Water pollution by fertilizers and pesticides. Organization for Economic Co-operation and Development, Paris

Ortiz ME, Marco A, Saiz M, Lizana M (2004) Impact of ammonium nitrate on growth and survival of six European amphibians. Arch Environ Contam Toxicol 47:234-239

Orton F, Carr JA, Handy RD (2006) Effects of nitrate and atrazine on larval development and sexual differentiation in the Northern leopard frog Rana pipiens. Environ Toxicol Chem 25:65-71

Räsänen K, Kruuk LEB (2007) Maternal effects and evolution at ecological timescales. Funct Ecol 21:408-421

Räsänen K, Laurila A, Merilä J (2003) Geographic variation in acid stress tolerance of the moor frog, Rana arvalis. I. Local adaptation. Evolution 57:352-362

Richter-Boix A, Llorente GA, Montori A (2006) Breeding phenology of an amphibian community in a Mediterranean area. Amphib Reptil 27:544-549

Rist L, Semlitsch RD, Hotz H, Reyer HV (1997) Feeding behavior, food consumption and growth efficiency of hemiclonal and parental tadpole of the Rana esculenta complex. Funct Ecol 11:735-742

Ritter WF, Bergstrom L (2001) Nitrogen and water quality. In: Ritter WF, Shirmohammadi A (eds) Agricultural nonpoint source pollution: watershed management and hydrology. Lewis Publishers, Boca Ratón, pp 59-90 
Rowe CL, Kinney OM, Nagle RD, Congdon JD (1998) Elevated maintenance costs in an anuran (Rana catesbeiana) exposed to a mixture of trace elements during the embryonic and early larval periods. Physiol Zool 71:27-35

Shinn C, Marco A, Serrano L (2008) Inter- and intra-specific variation on sensitivity of larval amphibians to nitrite. Chemosphere 71:507-514

Tilman D, Fargione J, Wolff B, D’Antonio C, Dobson A, Howarth R, Schindler D, Schlesinger WH, Simberloff D, Swackhamer D (2001) Forecasting agriculturally driven global environmental change. Science 292:281-284

United States EPA (1986) Quality criteria for water. EPA 440/5-86001. United States Environmental Protection Agency (US EPA), Washington

Vidal A (1966) Estudio biológico de las islas Pitiusas: Anfibios. Publ Inst Biol Apl 40:81-112

Vidal-Abarca MR, Montes R, Ramírez-Díaz L, Suárez ML (1987) El clima de la cuenca del Río Segura (S.E. de España): factores que lo controlan. Anales de Biología 12:1-28

Vidal-Abarca M, Suárez ML, Moreno JL, Gómez R, Sánchez I (2000) Hidroquímica de un río de características semiáridas (Río Chícamo: Murcia). Análisis espacio-temporal. Limnética 18: 57-73

Vitousek PM, Aber J, Howarth RW, Likens GE, Matson PA, Schindler DW, Schlesinger WH, Tilman GD (1997) Human alteration of the global nitrogen cycle: causes and consequences. Ecol Appl 7:737-750

Warkentin KM (1992) Microhabitat use and feeding rate variation in green frog tadpoles (Rana clamitans). Copeia 1992:731-740

Wasserssug RJ, Feder ME (1983) The effect of aquatic oxygen concentration, body size and respiratory behaviour on the stamina of obligate (Bufo americanus) and facultative airbreathing (Xenopus laevis and Rana berlandieri) anuran larvae. J Exp Biol 105:173-190

Watt PJ, Oldham RS (1995) The effect of ammonium nitrate on the feeding and development of larvae of the smooth newt, Triturus vulgaris (L.), and on the behaviour of its food source, Daphnia. Freshw Biol 33:319-324

Wilbur HM, Morin PJ, Harris RN (1983) Salamander predation and the structure of experimental communities: anuran responses. Ecology 34:1423-1429

Wright PM, Wright PA (1996) Nitrogen metabolism and excretion in bullfrog (Rana catesbeiana) tadpoles and adults exposed to elevated environmental ammonia levels. Physiol Zool 69:10571078

Xu Q, Oldham RS (1997) Lethal and sublethal effects of nitrogen fertilizer ammonium nitrate on common toad (Bufo bufo) tadpoles. Arch Environ Contam Toxicol 32:298-303 